\title{
PUZZLE ELEKTRONIK MONTESSORI SAND BOARD LETTER(SBL) UNTUK EDUKASI SUKU KATA BAHASA INDONESIA PADA ANAK USIA DINI
}

\author{
Indah Purwitasari Ihsan ${ }^{*}$, Muh. Sakir ${ }^{2}$, Farida Yusuf $f^{3}$ \\ ${ }_{1,2}$ Program Studi Teknik Elektro Fakultas Teknik Universitas Fajar Makassar \\ ${ }^{3}$ Jurusan Sistem Informasi Fakultas Sains dan Teknologi Universitas Islam Negeri Alauddin Makassar \\ *E-mail: indah.ihsan13@gmail.com
}

\begin{abstract}
Montessori is a learning method to stimulate children to reach their potential in all fields. In the field of reading literacy, one of the initial stages is how to stimulate initial reading skills, starting with introducing letters using the syllable learning method. The stimulation process must be in a fun and non-boring way of playing exploration so that children will not feel that they are learning, especially in the current state of the COVID-19 pandemic, where the learning process becomes boring for children because it has to be done at home. just. The purpose of this study is to create a learning technology in the form of an electronic Montessori Sand Board Letter (SBL) Puzzle for Indonesian syllables that can help stimulate early childhood according to the Montessori principle in recognizing syllables. The system development method uses the System Development Life-Cycle (SDLC) method. Based on the results of functional testing using the black box method, it is stated that the entire functional system is $100 \%$ functioning according to the system design. The results of testing and validation by Montessori practitioners state that the system has been made according to Montessori rules. Based on the results of usage observations, the Montessori Sand Board Letter (SBL) electronic puzzle for $85 \%$ Indonesian syllables can stimulate children's ability to recognize Indonesian syllables.
\end{abstract}

Keywords: Montessori, Electronic Puzze, Sand Board Letter

Abstrak - Montessori merupakan salah satu metode pembelajaran untuk menstimulasi anak dalam meraih potensinya di segala bidang. Pada bidang literasi membaca salah satu tahapan awal adalah bagaimana menstimulasi kemampuan membaca permulaan, dimulai dengan mengenalkan huruf-huruf menggunakan metode belajar suku kata. Proses stimulasi tersebut haruslah dengan cara eksplorasi bermain yang menyenangkan dan tidak membosankan sehingga anak tidak akan merasa bahwa ia sedang belajar, apatah lagi dalam kondisi pandemic covid-19 yang masih berlangsung hingga saat ini, dimana proses belajar menjadi membosankan bagi anak karena harus dilakukan di rumah saja. Tujuan dari penelitian ini adalah membuat sebuah teknologi pembelajaran berupa Puzzle elektronik Montessori Sand Board Letter(SBL) untuk suku kata Bahasa Indonesia yang dapat membantu menstimulasi anak usia dini sesuai prinsip Montessori dalam mengenal suku kata. Metode pengembangan sistem menggunakan Metode Sistem Development Life-Cycle(SDLC). Berdasarkan hasil pengujian fungsional menggunakan metode black box menyatakan bahwa seluruh fungsional sistem $100 \%$ berfungsi sesuai rancangan sistem. Hasil pengujian dan validasi oleh praktisi montessori menyatakan bahwa sistem telah dibuat sesuai kaidah Montessori. Berdasarkan hasil observasi penggunaan, Puzzle elektronik Montessori Sand Board
Letter(SBL) untuk suku kata Bahasa Indonesia 85\% dapat menstimulasi kemampuan anak dalam hal mengenal suku kata Bahasa Indonesia.

Kata Kunci: Montessori, Puzze Elektronik, Sand Board Letter

\section{PENDAHULUAN}

Anak Usia Dini dalam Peraturan Presiden (Perpres) Nomor 60 Tahun 2013 Bab 1 Pasal 1 Ayat 1 adalah bayi yang baru lahir hingga anak-anak yang belum genap berusia 6 tahun(style apa,. Nama, tahun1). Pada usia tersebut merupakan periode emas perkembangan anak karena sel-sel otaknya yang berkembang pesat dan saling terhubung dengan sangat cepat, untuk memaksimalkan perkembangan tersebut, anak harus diberikan stimulus yang tepat dengan memperhatikan kesiapan anak dan metode yang diberikan. Montessori merupakan salah satu metode pembelajaran untuk menstimulasi anak dalam meraih potensinya di segala bidang, dengan prinsip bahwa setiap individu harus mengedukasi dirinya sendiri, sedangkan tugas guru atau orang tua adalah mendampingi, menyediakan informasi serta alat pembelajaran kepada anak.

Potensi anak pada bidang literasi yaitu kemampuannya untuk dapat membaca dan menulis. Salah satu tahapan awal sebagai persiapan menuju tahap usia siap membaca adalah bagaimana mengenalkan bentuk dan bunyi huruf. Metode yang dianggap tepat untuk mengenalkan huruf yaitu menggunakan metode belajar suku kata sesuai prinsip montessori. Karena dunia anak adalah dunia bermain, maka proses stimulasi tersebut haruslah dengan cara eksplorasi bermain yang menyenangkan sehingga anak tidak akan merasa bahwa ia sedang mengedukasi dirinya sendiri yang secara tidak langsung terjadilah stimulus, dan hal terpenting dalam pelaksanaan stimulus tersebut adalah anak tidak boleh sampai merasa bosan apalagi jenuh. Apatah lagi hingga saat ini kita masih berada dalam situasi pandemic covid-19 yang mengharuskan proses pembelajaran di lakukan di rumah saja, sehingga hal tersebut bisa saja menambah kebosanan anak usia dini, maka dibutuhkanlah sebuah alat bantu untuk stimulasi kemampuan mengenal huruf pada anak dengan permainan suku kata yang dikemas dalam bentuk permainan Puzzle. 
Alat bantu yang telah ada sekarang berupa buku, permainan dalam bentuk aplikasi perangkat lunak, dan kartu huruf raba. Berdasarkan hasil pengamatan yang telah dilakukan oleh peneliti, kendala dari beberapa alat bantu tersebut diantaranya, buku yang mudah sobek karena akan jadi bahan mainan oleh anak usia dini, permainan dalam bentuk aplikasi beresiko anak akan terpapar gadget, hal tersebut tidak baik untuk perkembangan motorik dan kognitif anak usia dini, sedangkan kelemahan kartu huruf raba yaitu belum adanya huruf raba dalam bentuk permainan Puzzle yang bersifat elektronik dan interaktif.

Tujuan dari penelitian ini adalah untuk membantu menstimulasi kemampuan membaca awal pada anak usia dini sesuai prinsip montessori, dengan membuat sebuah teknologi pembelajaran berupa Puzzle elektronik Montessori Sand Board Letter(SBL) untuk suku kata Bahasa Indonesia. Pada alat tersebut terdapat kepingan Puzzle yang berisi suku kata yang dapat diraba teksturnya sehingga dapat menstimulasi perkembangan motorik anak, kepingan tersebut akan diletakkan pada board, jika penempatannya benar maka anak akan dapat mendengar suara berupa penyebutan dari suku kata tersebut, sehingga terjadi sinkronisasi antara huruf yang anak raba dengan penempatan dan bunyi suku kata yang sesuai, hal tersebut dapat menstimulasi perkembangan motorik dan perkembangan kognitif anak dari segi Bahasa.

\section{METODE PENELITIAN}

Metode pada penelitian ini mengadopsi metode pengembangan sistem yaitu System Development LifeCycle(SDLC) yang terdiri dari lima tahapan(sumber), yaitu:

\section{Tahapan Requirement Analysis}

Pada tahap ini akan dilakukan studi kelayakan dari penelitian yang akan dibuat dengan cara observasi cara belajar suku kata, studi literature, diskusi bersama tim peneliti dan sharing bersama penggiat Montessori. Pada tahap ini juga akan dilakukan analisa kebutuhan dan persyaratan dari alat yang akan dibuat kemudian dituangkan dalam dokumen System Requirement Specification (SRS).

2. Tahapan System Design

Setelah membuat dokumen SRS, langkah berikutnya adalah melakukan desian sistem. Pada tahap ini dibuat perancangan konseptual dan perancangan logis berupa flowchart sistem serta blok diagram alat, serta membuat perancangan fisik berupa protoype dari alat yang akan dibuat.

3. Tahapan Implementation

Pada tahap ini merupakan tahap mengimplementasikan seluruh rancangan yang telah dibuat sebelumnya dan mengembangkan prototype menjadi alat yang sesungguhnya.

\section{Tahapan Testing}

Alat yang telah dibuat akan diujicobakan untuk mengevaluasi dan menemukan kekurangan dan kesalahan dari alat tersebut sehingga bisa diperbaiki dan untuk memastikan alat tersebut dapat berjalan sesuai rancangan dan tujuan serta menjadi layak pakai. Teknik uji coba menggunakan metode black box testing dan observasi.

5.Tahapan Operation and Maintenance.

Setelah melalui tahap testing dan dinyatakan layak pakai, maka alat yang dibuat akan diterapkan untuk digunakan sebagai alat bantu dalam pengenalan suku kata Bahasa Indonesia untuk anak usia dini.

\section{HASIL DAN PEMBAHASAN}

\section{A. Unified Modelling Sistem (UML)}

UML merupakan alat perancangan sistem yang berorientasi pada objek. Konsep ini menganalogikan sistem seperti kehidupan nyata yang didominasi oleh obyek dan digambarkan atau dinotasikan dalam simbol-simbol yang cukup spesifik (Haviluddin, 2011). Salah satu diagram pada UML adalah diagram Use Case. Use Case diagram menggambarkan fungsi tertentu berupa interaksi terkait scenario untuk tujuan melengkapi sistem(Sonata, 2019). Pada sistem ini user terbagi dua yaitu orang tua/guru dan anak usia dini. Berikut diagram use casenya :

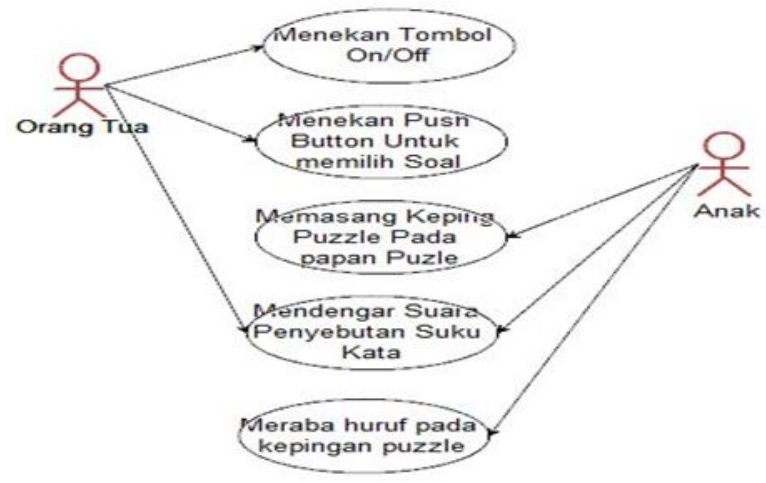

Gambar 1. Diagram Use Case

\section{B. Flowchart Sistem}

Flowchart merupakan rangkaian symbol-simbol yang digunakan untuk penggambaran secara grafik dari langkahlangkah dan urutan prosedur suatu program(Ilham Budiman, Sopyan Saori, Ramdan Nurul Anwar, Fitriani \& Pangestu, 2021). Berikut merupakan flowhart sistem : 


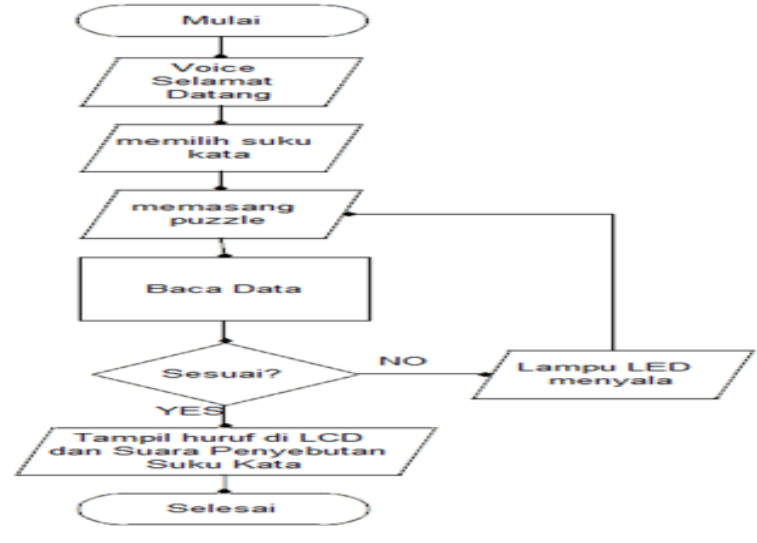

Gambar 2. Flowchart Sistem

\section{Blok Diagram Sistem}

Blok diagram sistem menggambarkan komponen-komponen hardware yang bekerja secara terintegrasi dalam membentuk suatu sistem kerja alat (Susana et al., 2017). Berikut merupakan blok diagram alat:

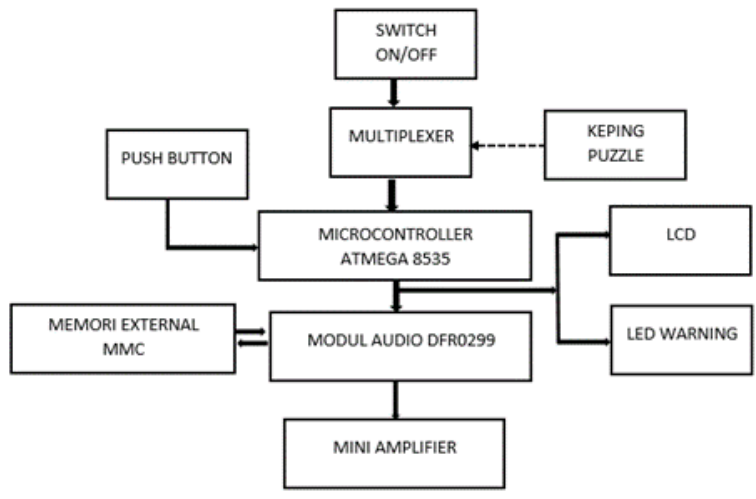

\section{Gambar 3. Blok Diagram Alat}

D. Perancangan Box Penyimpanan Kepingan Puzzle

Box penyimpanan digunakan untuk menyimpan kepingan kepingan puzzle dan board permainan agar tersimpan rapi dan tidak tercecer. Berikut merupakan perancangan Box penyimpanan Kepingan Puzzle:

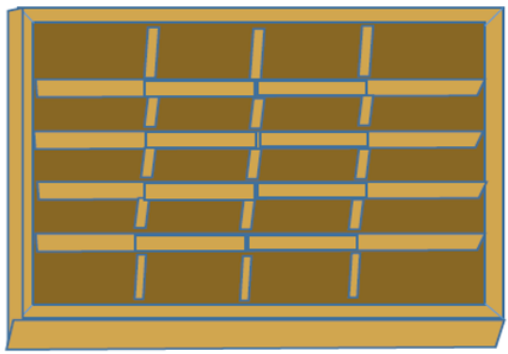

Gambar 4. Perancangan Box Penyimpanan Kepingan Puzzle

E. Perancangan Papan Puzzle

Papan puzzle berupa perangkat keras yang berisi rangkaian elektronik, papan tersebut akan dibuat berdasarkan ukuran, bentuk dan bahan yang dapat menutupi perangkat keras dan aman, mudah digunakan serta memiliki nilai estetika yang menarik. Berikut perancangan papan puzzle:

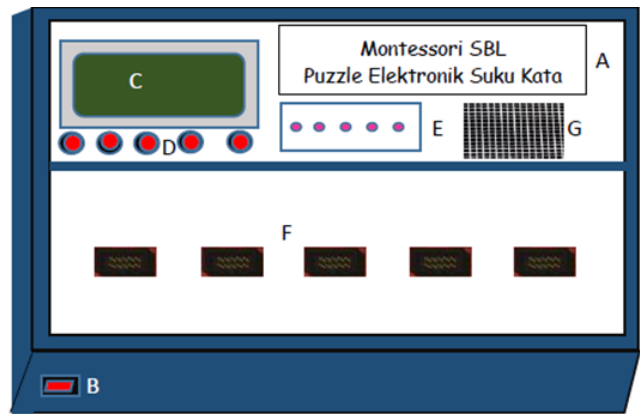

Gambar 5. Perancangan Papan Puzzle

Keterangan ;

A.Nama Permainan

B.Switch On/Off

C.LCD (LM032L)

D.Push Button

E.Lampu LED

F.Header puzzle

G.Mini Amplifier

F. Perancangan Keping Puzzle

Berikut merupakan perancangan keeping puzzle tampak atas:

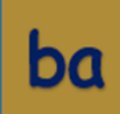

Gambar 6. Perancangan keping puzzle tampak atas

Kepingan puzzle berisi suku kata gabungan konsonan dan vocal, huruf - huruf tersebut nantinya akan dibuat kasar berpasir, sehingga anak-anak dapat meraba hurufnya agar menstimulasi motorik dan daya ingatnya tentang bentuk huruf yang disentuh. contoh rancangan kepingan puzzle untuk suku kata gabungan konsonan $\mathrm{b}$ dan vocal a, i, u, e, o
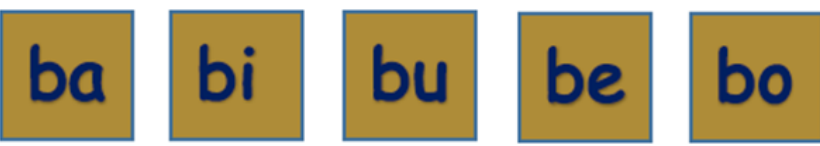

Gambar 7. Perancangan keping puzzle suku kata

Setiap potongan puzzle dirancang agar memiliki data biner yang berbeda. Hal ini dilakukan agar mikrokontroler dapat membedakan setiap potongan puzzle yang terpasang pada papan permainan. Berikut merupakan hasil dari kegiatan membuat perancangan keeping puzzle tampak bawah. 


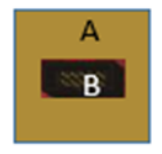

Gambar 8. Perancangan keeping puzzle tampak bawah

Keterangan ;

A.Keping puzzle

B.Socket

\section{G. Puzzle Elektronik Montessori Sand Board Letter}

\section{Box Penyimpanan Kepingan Puzzle}

Box penyimpanan kepingan puzzle dibuat sesuai gambar dari perancangan yang telah dibuat sebelumnya. Box dibuat dari kayu dan tripleks yang ringan. Berikut merupakan foto box penyimpanan kepingan puzzle :

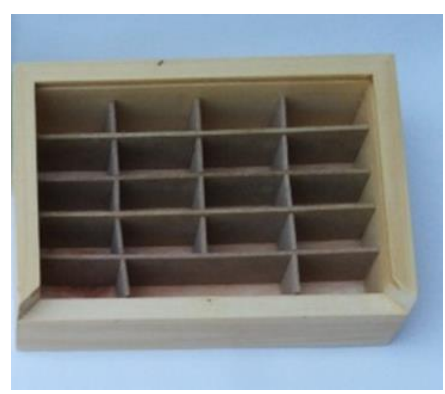

Gambar 9. Foto Box Penyimpanan Kepingan Puzzle

\section{Keping Puzzle}

Keping puzzle dibuat dari papan kayu dan tripleks. Huruf diatas kepingan puzzle dilapisi lem pasir agar bertekstur kasar berpasir, sehingga anak-anak dapat meraba hurufnya agar menstimulasi motorik dan daya ingatnya tentang bentuk huruf yang disentuh. Berikut merupakan foto dari kepingan puzzle tampak atas:

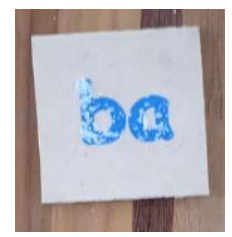

Gambar 10. Foto Kepingan Puzzle Tampak Atas

\section{Papan Puzzle Elektronik}

Papan/board dibuat dari kayu dengan finishing triplek sehingga aman digunakan oleh anak usia dini.

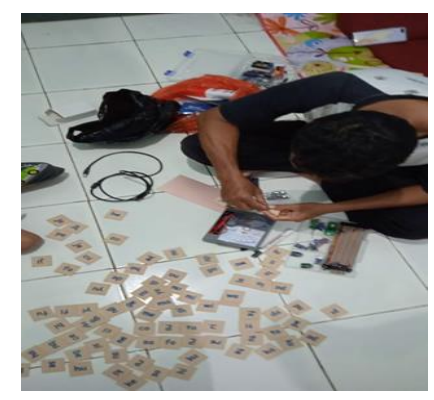

ambar 11. Foto Proses Pembuatan Board Puzzle

Berikut merupakan rangkaian komponen elektronik pada board puzzle :

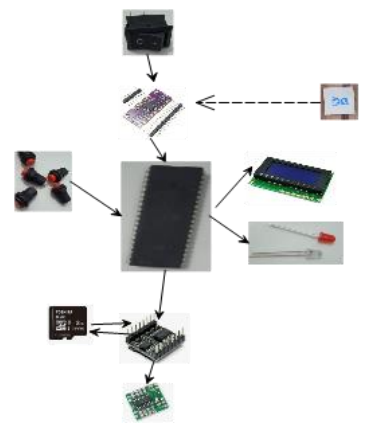

Gambar 12. Foto Krangkaian elektronik pada Board Puzzle

H. Pengujian

Pengujian meliputi pengujian fungsional dari alat, validasi alat, serta observasi terhadap penggunaan puzzle elektronik selama beberapa waktu.

\section{Kegiatan Pengujian Fungsional}

Pengujian fungsional merupakan pengujian yang dilakukan untuk mengecek keseluruhan fungsi dari system apakah sudah berjalan sesuai perancangan dan tujuan yang diharapkan(Khasanah et al., 2018). Metode pengujian fungsional menggunakan metode black box. Pengujian dilakukan oleh satu orang praktisi teknologi informasi sebanyak 5 kali pengujian

Tabel 1. Rekapitulasi Hasil Pengujian Fungsional

\begin{tabular}{|c|c|c|c|c|c|c|c|c|c|c|c|c|}
\hline \multirow{3}{*}{$\begin{array}{c}\text { Pengyjan } \\
\mathrm{Ke}\end{array}$} & \multicolumn{10}{|c|}{ Deskipsi Fungsional } & \multirow{2}{*}{\multicolumn{2}{|c|}{ Total Jawaba }} \\
\hline & \multicolumn{2}{|c|}{1} & \multicolumn{2}{|c|}{2} & \multicolumn{2}{|c|}{3} & \multicolumn{2}{|c|}{4} & \multicolumn{2}{|c|}{5} & & \\
\hline & $B$ & $T$ & $B$ & $T$ & 8 & $T$ & 8 & $T$ & $B$ & $T$ & $B$ & $T$ \\
\hline 1 & 1 & 0 & 1 & 0 & 1 & 0 & 1 & 0 & 1 & 0 & 5 & 0 \\
\hline 2 & 1 & 0 & 1 & 0 & 1 & 0 & 1 & 0 & 1 & 0 & 5 & 0 \\
\hline 3 & 1 & 0 & 1 & 0 & 1 & 0 & 1 & 0 & 1 & 0 & 5 & 0 \\
\hline 4 & 1 & 0 & 1 & 0 & 1 & 0 & 1 & 0 & 1 & 0 & 5 & 0 \\
\hline 5 & 1 & 0 & 1 & 0 & 1 & 0 & 1 & 0 & 1 & 0 & 5 & 0 \\
\hline Total & 5 & 0 & 5 & 0 & 5 & 0 & 5 & 0 & 5 & 0 & 15 & 0 \\
\hline \begin{tabular}{|l|} 
Presentage \\
\end{tabular} & 100 & 100 & 100 & 100 & 100 & 100 & 100 & 100 & 100 & 100 & 100 & 100 \\
\hline
\end{tabular}

Tabel 1 menunjukkan bahwa untuk semua item fungsi pada 5 kali pengujian mendapatkan hasil yang sama, yaitu berhasil berfungsi. Berdasarkan hasil pengujian fungsionalitas yang telah dilakukan oleh seorang praktisi teknologi dan informasi sebanyak 5 kali menyatakan bahwa keseluruhan fungsionalitas $100 \%$ dapat berfungsi dengan baik.

\section{Kegiatan Validasi}

Validasi dilakukan untuk menvalidasi komponen kepingan puzzle yang dibuat apakah sudah sesuai kaidah Montessori atau belum. Penguji adalah seorang praktisi/ guru PAUD serta penggiat montessori. Berikut merupakan hasil validasi: 


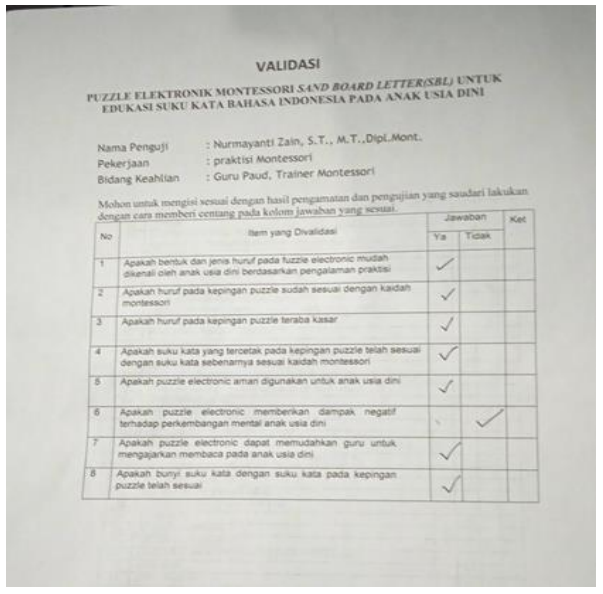

Hasil dari pengujian menunjukkan bahwa teknologi pembelajaran yang dibuat telah sesuai dengan kaidah Montessori dan tidak berdampak negative pada perkembangan mental anak.

\section{Observasi Pengunaan}

Observasi dilakukan selama kurang lebih 2 bulan penggunaan teknologi pembelajaran terhadap anak usia dini sebanyak 2 anak yang didampingi oleh orang tua maupun guru dengan bergantian menggunakan teknologi pembelajaran. Berikut merupakan rekapitulasi hasil observasi

Tabel 7. Rekapitulasi Hasil Observasi

\begin{tabular}{|c|c|c|c|c|c|c|c|c|c|c|c|c|}
\hline \multirow{3}{*}{ Sampla be- } & \multicolumn{12}{|c|}{ Item Yang Dobservas } \\
\hline & \multicolumn{2}{|c|}{1} & \multicolumn{2}{|c|}{2} & \multicolumn{2}{|c|}{3} & \multicolumn{2}{|c|}{4} & \multicolumn{2}{|c|}{5} & \multicolumn{2}{|c|}{6} \\
\hline & $Y$ & T & $y$ & I & Y & I & $Y$ & I & $\mathrm{y}$ & T & $Y$ & T \\
\hline 1 & $i$ & & 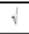 & & 1 & & 1 & & 1 & & 1 & \\
\hline 2 & i & & $i$ & & 1 & & $\sqrt{ }$ & & 1 & & 1 & \\
\hline
\end{tabular}

Hasil dari observasi penggunaan teknologi pembelajaran yaitu puzzle elektronik Montessori sand board letter menunjukkan bahwa teknologi pembelajaran yang dibuat dapat menjadi salah satu alternative tools pembelajaran mengenalkan suku kata Bahasa Indonesia untuk proses belajar membaca permulaan

\section{KESIMPULAN}

Puzzle elektonik yang telah dibuat dapat membantu menstimulasi kemampuan membaca awal pada anak usia dini sesuai prinsip montessori Semua komponen elektronik pada rangkaian board telah berjalan sesuai fungsinya masing-masing. Alat mampu membedakan kepingan puzzle salah atau benar dan mampu mengeluarkan suara bunyi huruf yang sesuai dengan kepingan puzzle yang diletakkan pada board. Anak dapat dengan mudah meraba tekstur huruf yang ada pada kepingan puzzle, hal ini menstimulasi kemampuan mengingat huruf serta menstimulasi kemampuan menulis. Teknologi yang telah dibuat yaitu puzzle elektronik Montessori sand board letter telah sesuai dengan kaidah Montessori dan tidak berdampak negative pada perkembangan mental anak serta dapat menjadi salah satu alternative tools pembelajaran pada metode Montessori mengenalkan suku kata Bahasa Indonesia untuk proses belajar membaca permulaan, hal tersebut berdasarkan hasil dari validasi dan observasi penggunaan teknologi.

\section{DATAR ACUAN}

[1] Aini, O., \& Ayu, K. C, "Pengembangan Game Puzzle Sebagai Edugame Berbasis Android Untuk Meningkatkan Kemampuan Berpikir Matematika Siswa SD. 3", (No. 1, April), 74-79. https://doi.org/https://doi.org/10.31764/jtam.v3i1.768, 2019.

[2] Cicilia Apriani, Kasiyati, T, "Efektifitas metode kupas rangkai suku kata dalam meningkatkan kemampuan membaca permulaan bagi anak kesulitan membaca" E-jupekhu (jurnal ilmiah pendidikan khusus), 2 (September), 835-844, 2013.

[3] Handayani. Tri Vincentia, Afsari. Ari, H. F, "Dongeng Sebagai Stimulan Awal Peningkatan Minat Baca Bagi Siswa Paud Bunda Hajar Jatinangor", Jurnal Pengabdian Kepada Masyarakat, 2 (Nomor 9), 3-6, 2015.

[4] Haviluddin, "Memahami Penggunaan UML ( Unified Modelling Language )", Jurnal Informatika Mulawarman, 6(1 februari), 1-15. https://doi.org/http://dx.doi.org/10.30872/jim.v6i1.16, 2011.

[5] Hidayah, N. A, "Peningkatan Keterampilan Bahasa (Membaca Awal) Anak Kelompok B Dalam Zona Literasi Di Sentra Readines Tk It Permata Hati Ngaliyan" (Skripsi). Universitas Negeri Semarang, 2019.

[6] Ilham Budiman, Sopyan Saori, Ramdan Nurul Anwar, Fitriani, M. Y., \& Pangestu, "Analisis Pengendalian Mutu Di Bidang Industri Makanan (Studi Kasus: UMKM Mochi Kaswari Lampion Kota Sukabumi)", Jurnal Inovasi Pendidikan, 1(10, Maret), 2021.

[7] Kementrian Hukum Dan Hak Asasi Manusia Republik Indonesia, "Peraturan Presiden Republik Indonesia Nomor 60 tahun 2013 tentang pengembangan anak usia dini holistik-integratif. dalam peraturan Presiden Republik Indonesia. Kementrian Hukum Dan Hak Asasi Manusia Republik Indonesia”, 2013.

[8] Khasanah, F. N., Informatika, T., Testing, B., Testing, B. B., \& Based, L, "Pengujian Fungsional Dan Non Fungsional Aplikasi Informasi Telepon Darurat Berbasis Android" 3(1), 79-90, 2018. 
[9] Masyrofah, "Model Pembelajaran Montessori Anak Usia Dini”, 02(02 : Juli-Desember), 105-116, 2017.

[10] Montessori, M, The Montessori Method. Transaction Publisher, 2014.

[11] Mustikawati, R, "Upaya peningkatan keterampilan membaca permulaan dengan metode suku kata ( syllabic method ) pada siswa kelas I Sd Negeri Nayu Barat III Banjarsari Surakarta tahun 2014/2015. Jurnal Ilmiah Mitra Swara Ganesha, 2(1), 41-56, 2015.

[12] Sonata, F, "Pemanfaatan UML (Unified Modeling Language) Dalam Perancangan Sistem Informasi ECommerce Jenis Customer-To-Customer" Jurnal Komunika: Jurnal Komunikasi, Media Dan Informatika, 8(1), 22. https://doi.org/10.31504/komunika.v8i1.1832, 2019.

[13] Sugeng, H. M., Tarigan, R., \& Sari, N. M, "Gambaran Tumbuh Kembang Anak pada Periode Emas Usia 0-24 Bulan di Posyandu Wilayah Kecamatan Jatinangor of age 0-24 Months in Posyandu Jatinangor Subdistrict. JSK”, Jurnal Sistem Kesehatan”, 4(Nomor 3 Maret), 96-101, 2019.

https://doi.org/https://doi.org/10.24198/jsk.v4i3.21240, 2019.

[14] Susana, R., Albayumi, U. A., \& Bugar, F. S, Implementasi Function Block Diagram Pada, 2017. 